\title{
Amorphous drug-polymer salt with high stability under tropical conditions and fast dissolution: The case of clofazimine and poly(acrylic acid)
}

\author{
Yue Gui, ${ }^{1}$ Erin C. McCann, ${ }^{1}$ Xin Yao, ${ }^{1}$ Yuhui Li, ${ }^{1}$ Karen J. Jones,${ }^{2}$ Lian Yu*1 \\ ${ }^{1}$ School of Pharmacy, ${ }^{2}$ Zeeh Pharmaceutical Experiment Station, School of Pharmacy, \\ University of Wisconsin-Madison, Madison, WI 53705, USA
}

\section{Supporting Information}

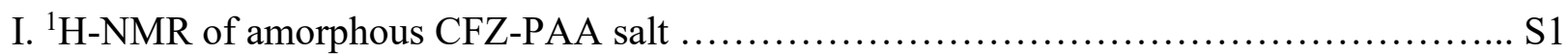

II. TGA of amorphous CFZ-PAA salt ......................................... S2

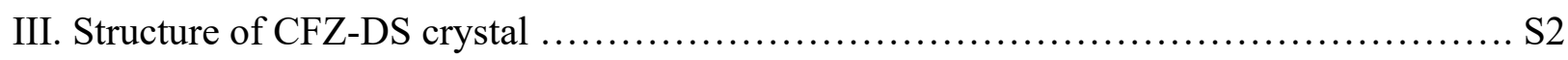

\section{I. ${ }^{1}$ H-NMR of amorphous CFZ-PAA salt}
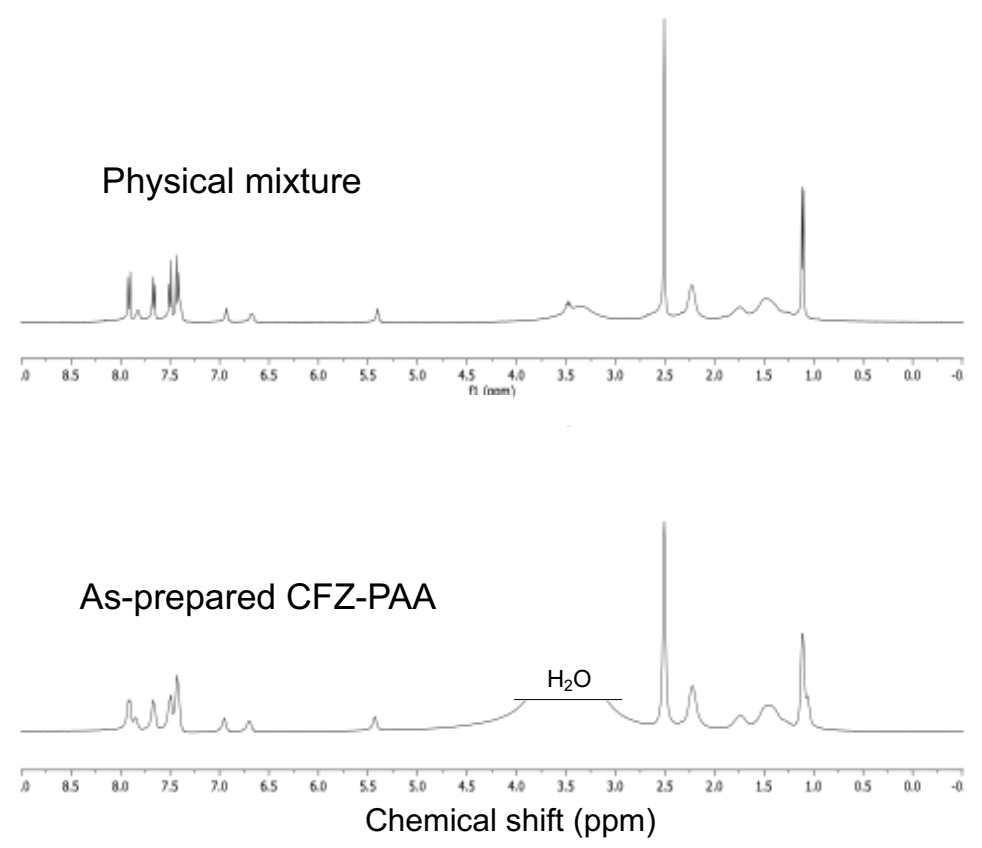

Figure S1. ${ }^{1} \mathrm{H}-\mathrm{NMR}$ shows no decomposition after preparation of amorphous CFZ-PAA (75 wt \% drug) salt. 


\section{TGA of amorphous CFZ-PAA salt}

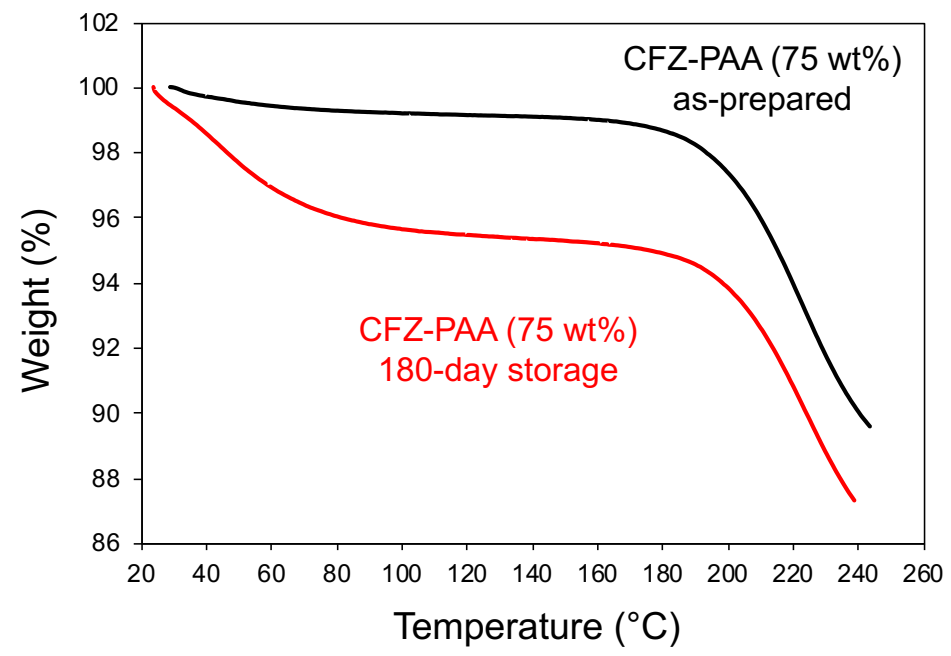

Figure S2. Water content of amorphous CFZ-PAA salt before (black) and after (red) tropical conditions $\left(40{ }^{\circ} \mathrm{C}\right.$ and $\left.75 \% \mathrm{RH}\right)$ storage detected by TGA. Comparing the weight loss at $100{ }^{\circ} \mathrm{C}$, water content in amorphous CFZ-PAA salt increases from $1 \mathrm{wt} \%$ to $5 \mathrm{wt} \%$ after $180 \mathrm{~d}$ storage.

\section{Structure of CFZ-DS crystal}

Table S1. Crystal structure of CFZ-DS salt.

\begin{tabular}{|c|c|}
\hline Crystal & CFZ-DS salt \\
\hline$T, \mathrm{~K}$ & 100 \\
\hline space group & $\mathrm{P} \overline{1}$ \\
\hline$a, \AA$ & 10.924 \\
\hline$b, \AA$ & 13.785 \\
\hline$c, \AA$ & 14.622 \\
\hline$\alpha, \operatorname{deg}$ & 116.39 \\
\hline$\beta, \operatorname{deg}$ & 91.27 \\
\hline$\gamma, \operatorname{deg}$ & 108.04 \\
\hline$V, \AA^{3}$ & 1842.24 \\
\hline$Z / Z$ & $2 / 1$ \\
\hline$R \%$ & 5.3 \\
\hline
\end{tabular}




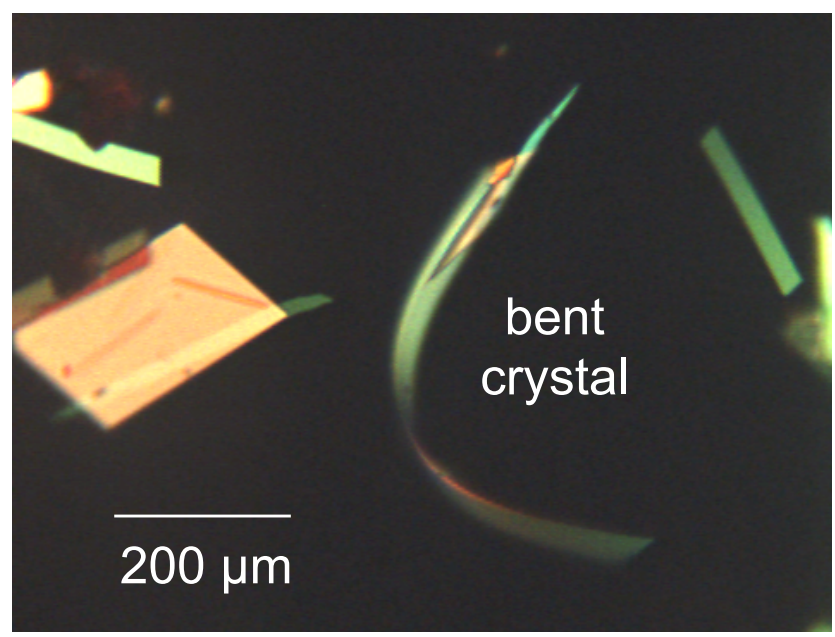

Figure S3. CFZ-DS crystals suspended in SGF are flexible and can bend in the media. The picture was taken using a polarized light microscope for an SGF droplet containing CFZ-DS crystals. 